Review

\title{
Gold Nanoparticles for Drug Delivery and Cancer Therapy
}

\author{
Sarkar Siddique ${ }^{1}$ and James C. L. Chow ${ }^{2,3, *(D)}$ \\ 1 Department of Physics, Ryerson University, Toronto, ON M5B 2K3, Canada; sarkar.siddique@ryerson.ca \\ 2 Radiation Medicine Program, Princess Margaret Cancer Centre, University Health Network, \\ Toronto, ON M5B 2K3, Canada \\ 3 Department of Radiation Oncology, University of Toronto, Toronto, ON M5T 1P5, Canada \\ * Correspondence: james.chow@rmp.uhn.ca; Tel.: +1-416-946-4501
}

Received: 24 April 2020; Accepted: 29 May 2020; Published: 31 May 2020

\begin{abstract}
Nanomaterials are popularly used in drug delivery, disease diagnosis and therapy. Among a number of functionalized nanomaterials such as carbon nanotubes, peptide nanostructures, liposomes and polymers, gold nanoparticles (Au NPs) make excellent drug and anticancer agent carriers in biomedical and cancer therapy application. Recent advances of synthetic technique improved the surface coating of Au NPs with accurate control of particle size, shape and surface chemistry. These make the gold nanomaterials a much easier and safer cancer agent and drug to be applied to the patient's tumor. Although many studies on Au NPs have been published, more results are in the pipeline due to the rapid development of nanotechnology. The purpose of this review is to assess how the novel nanomaterials fabricated by Au NPs can impact biomedical applications such as drug delivery and cancer therapy. Moreover, this review explores the viability, property and cytotoxicity of various $\mathrm{Au}$ NPs.
\end{abstract}

Keywords: nanoscale materials; gold nanoparticles; functionalized nanomaterials; drug delivery; thermal therapy; radiation therapy; medical imaging; gold nanoparticle-based cancer therapy; anticancer agent

\section{Introduction}

Gold nanoparticles (Au NPs) are effective radiosensitizers in medical applications such as drug delivery and cancer therapy. In biomedical and cancer therapy applications, Au NPs can act as a contrast agent and dose enhancer in image-guided nanoparticle-enhanced radiotherapy using kilovoltage cone-beam computed tomography [1,2]. With recent advances of synthesis and fabrication methods in nanomaterials, particle variables such as size, composition, morphology and surface chemistry can be controlled easily by precise technology [3]. Moreover, biocompatible surface coating can be added onto the NP surface to provide stabilization under physiological condition. The integration of functional ligands as coating through surface chemistry on the NPs enables them to perform multiple biomedical functions in the molecular or cellular level simultaneously. Applications of these nanomaterials include contrast agents in multimodal imaging, carriers in drug delivery and enhancers in cancer therapy. In this review, we will highlight various synthesis methods to fabricate Au NPs. We will explore different applications of nanomaterials in drug delivery and cancer therapy such as plasmid deoxynucleic acids vector delivery, ribonucleic acids delivery and gold nanoparticle-based therapy.

Tremendous technological interest have been given to Au NPs due to their unique optical properties, ease of synthesis and chemical stability. The particles can be used in biomedical applications such as cancer treatment, biological imaging, chemical sensing, and drug delivery [4-6]. However, their potential toxicity and health impact need to be explored thoroughly, before they can be used in 
clinical settings [7]. Considerable interest has been given to nanostructures in the past few years due to their properties, such as safe delivery and ability to act as a therapeutic agent. Several therapeutic approaches have been reported to make use of NPs, such as in anticancer drug delivery, molecular diagnosis for disease detection and nanoscale immunotherapy. These areas show high potential for future clinical implementation [8]. Recent studies on NPs have given insight on how to develop new targeted therapies, systemic cancer treatments and identification of novel oncogenic targets [9]. Commonly used nanomaterials in biomedical application are Au NPs, liposomes, carbon nanotubes, polymeric micelles, graphene, ferrous or ferric oxide NPs, and quantum dots [10]. Human exposure to engineered nanomaterials is inevitable due to recent advances of NP-based applications. NPs provide plentiful advantages from industrial and consumer perspective. NPs are used in many applications and their properties determine their usage in application [11-13]. Some of the important properties of NPs are size, melting point, chemical reactivity and particle surface area. The size of NPs is generally below $100 \mathrm{~nm}$ and they have low melting point, high chemical reactivity and large external surface area [14]. Recently, NP-based drug delivery attracted increasing attention [15]. Au NPs are one of the popular NPs and have been widely studied in cancer theranostics. The application of Au NPs can be traced back to the middle age and that is why they are also known as potable gold [16]. Some of the unique properties of Au NPs prominent in medical application are the high x-ray absorption coefficient, localized surface plasmon resonance and radioactivity [17]. Au NPs also display amazing electronic and optical properties that can enable controllable interactions with organic molecules having electron-donating groups. With the advances of functionalized Au nanomaterials, their usages have been increased with the potential to be implemented in many more applications [18].

From the drug administration for patients, whose degradation, movement, drug accumulation in tumor and body excretion follow complex theories, which compromising of vascular morphology and blood flow rate. As the injected dose transverses into the patient's body, the drug accumulation and kinetics fate are dictated by factors such as spatial diameter, geometry, number of and length of blood vessels. When the drug transports to the target destination, the efficacy of optimal dose uptake is reduced by the patient's defense mechanism that tries to keep foreign materials such as viruses, drug chemicals, bacteria and sensor devices out of the body [19]. Biomaterials offer the ability to improve upon medical technologies through increased control of the type and concentration of immune signals delivered. With the advances of surface coating technology, surface functionalization of Au NPs becomes possible. Different functional groups such as PEG, ssDNA, antibody, peptide, drug, florescence marker and siRNA can be attached on the particle surface as shown in Figure 1 . This makes Au NPs act as molecular sensors, therapeutic agents, and vehicles for imaging agent and drug delivery [20].

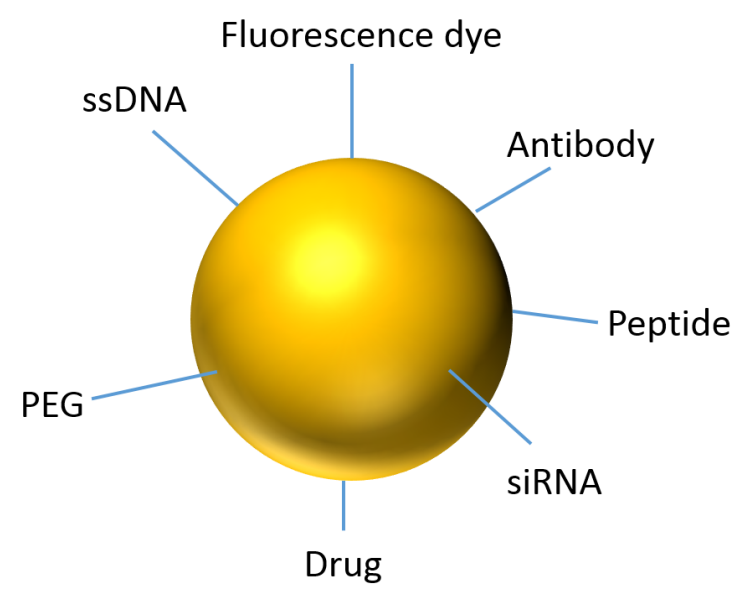

Figure 1. Representation of an Au NP for theranostics. 


\section{Synthesis and Properties}

Although there are many methods available to synthesize Au NPs, they are generally synthesized by the colloidal method [21,22]. This method utilizes a reducing agent, a metal precursor, and a stabilizing agent, which allow an easy tuning of shape, size, and optical properties of the nanostructure. The Au nanostructures that can be synthesized using this method are spheres, nanorods, and nano-cages [23]. Another less common nanostructure being used more recently is the hollow Au NPs, which can be synthesized using galvanic replacement [24]. Brust and Schiffrin developed a one-pot method to synthesize Au NPs, and the method can produce many different monolayer-protected $\mathrm{Au}$ NPs in a short period of time [25]. The method utilizes tetrachloroaurate $\left(\mathrm{AuCl}_{4}\right)$ salt, reduced with sodium borohydride $\left(\mathrm{NaBH}_{4}\right)$ with the desired ligand. Instead of using $\mathrm{NaBH}_{4}$, citrate can be used as reductant. However, no matter it is the citrate or $\mathrm{NaBH}_{4}$ used in the reduction method, post-treatment (e.g., dialysis) is necessary to obtain the stability and purity of Au NPs [26]. Ligand determines the core size of Au NPs, which is in the range of 1.5-6 nm. If the application requires Au NPs larger than $6 \mathrm{~nm}$, it can be synthesized using other methods such as the ripening approaches or citrate reduction of the $\mathrm{Au}$ salt [26]. Another common method for synthesizing monolayer protected Au NPs is the place exchange reaction. This method displaces the ligands of Au NPs in the equilibrium process [27]. For most biomedical applications, the preparation of Au NPs follows the bottom-up method [21-27]. A method involves the reduction of hydrogen tetrachloroaurate by sodium borohydride or sodium citrate [28]. Stabilizing or capping agents are used to avoid agglomeration and precipitation. Polyethyleneimine (PEI) is a suitable choice of stabilizing agent due to its concurrent role as a delivery and capping agent for nucleic acids. The high density of amine groups and branch PEI enable compound to form NP complexes by reacting to the nucleic acids [29]. PEI-coated Au NPs and their conjugate nucleic acids can be prepared using two approaches: (1) DNA or siRNA condensation onto PEI-capped Au NP monolayer; (2) ionic DNA or SiRNA and PEI onto the Au NP core [30]. PEGylation is a process modifying the particle surface area by the Polyethylene Glycol (PEG). This is a common method of reducing the premature clearance of NPs in circulation [31]. Alternative surface medication strategies include conditional PEG removal, substitute polymer and biomimetic modification of surface [32,33]. A summary of different synthetic methods for Au and other metallic NPs with different sizes can be found in Table 1 [21].

Table 1. Synthetic methods for different metallic NPs and their typical size distribution [21].

\begin{tabular}{ccc}
\hline Type of NPs & Synthetic Method & NP Size (nm) \\
\hline $\mathrm{Au}$ & Sol-gel micro reactors & $5-50$ \\
\hline $\mathrm{Au}, \mathrm{Ag}, \mathrm{Pd}, \mathrm{Pt}$ & PVD into liquid substrate & $2-10$ \\
\hline $\mathrm{Pd}, \mathrm{Pt}$ & Reduction in acidic environment & $3-40$ \\
\hline $\mathrm{Au}$ & Reduction process & $2-40$ \\
\hline $\mathrm{Au}, \mathrm{Cu}$ & $\gamma$-Irradiation & $3-30$ \\
\hline $\mathrm{Cu}$ & $\mathrm{pH}$ control of Cu complexes & $48-150$ \\
\hline $\mathrm{Au}, \mathrm{Ag}, \mathrm{Pd}$ & Biosynthesis & $9-25$ \\
\hline $\mathrm{Ag}$ & Wet chemistry & $20-60$ \\
\hline
\end{tabular}

At the early stage of using Au NPs, particle size was controlled by varying the ratio of the reducing agents such as sodium citrate, sodium borohydride and hydroxylamine ascorbic acid with $\mathrm{HAuCl}_{4}$. Particle size is tunable by the activity of the $\mathrm{Au}$ precursor and power of the reducing agents. A novel approach to change the size of Au NPs in the citrate reduction is to change the chloride ion concentration. The Au NP size can be tuned from 19 to $47 \mathrm{~nm}$ using this method [34]. In another approach, Poly $\left(\mathrm{N}_{1} \mathrm{~N}^{\prime}\right.$-diethylaminoethyl methacrylate) was used to stabilize the Au NPs in tetrachloroauric acid with citrates in acidic conditions. In the reacting mixture, the $\mathrm{pH}$ has significant 
effect on the size, morphology and polydispersity of the Au NPs. Size specifically can be changed by varying the $\mathrm{pH}$ of solution or solvent type [35]. In addition, $\mathrm{pH}$ was used to control the particle size in glutathione-capped Au NPs, where the size ranges from 5.5 to $8.0 \mathrm{~nm}$. This method is based on polymeric NPs precursors, $\mathrm{Au}$ (I) glutathione polymers, that changes size and density based on the $\mathrm{pH}$. A lower $\mathrm{pH}$ favors larger and denser precursors, which leads to larger Au NPs, and higher $\mathrm{pH}$ favors smaller and denser precursors resulting in smaller Au NPs [36].

In the seed-mediated synthesis of Au NPs, the chemical components determine the shape and rate of the NP formation. Halide is used to adjust the reduction potential of the Au ions and species in the solution and passivate the particle surface. Therefore, Halides can be used to control the reaction kinetics and enable the selective synthesis of NPs with different shapes [37]. Silver ions are also used to access various particle shapes by controlling the growth of Au NPs through surface passivation. The density of the Ag coverage can be adjusted by the concentration and type of the halide in the solution [38]. Gold silica nano-shells consist of silica cores within a tiny overly of Au, where the first Au particle is easily tunable to the near infrared (NIR) [39]. Seed-mediated growth is used to fabricate solid silica nano-shell, where the seeds of Au colloid are linked to the silica cores. They can induce cancer cell kill by photothermal effect. In vitro silica-based Au nano-shells were tested as targeted therapy probes for prostrate, breast, brain and liver cancer. In scatter-based imaging, the large size of the nano-shell provides clear advantage. Gold nanorods are smaller than Au nano-shells and they can easily be adjusted to NIR region by simply modifying their aspect ratio. Their small size allows them to have high absorption coefficients and narrow spectral bandwidths. The Au nanorods have two absorption peaks for the longitudinal and transverse resonances. Longitudinal resonance can range from the visible to the NIR wavelength, where transverse resonance occurs at $520 \mathrm{~nm}$. Gold nanorods have superior cross-section vs. Au silica and Au-Au sulfide NPs, when normalizing for the particle size differences. Their heating per gram of $\mathrm{Au}$ is at least 6 times faster than Au silica nano-shell, but Au silica has significant larger photothermal transduction cross-section per particle basis. Gold-gold sulfide NP has small size. Some examples of Au-Au sulfide are hollow Au nano-shells and Au nano-cages, where both have delivery advantage for photothermal ablation over larger Au NPs. Hollow Au NPs consist of a thin Au shell with a hollow center. Gold hollow shells can be fabricated using Co or Ag NPs, then oxidizing this material with chloroauric acid. Using this process, a thin Au shell can be created. Gold nano-cages are synthesized by creating a template of Ag NPs, then replacing the $\mathrm{Ag}$ with $\mathrm{Au}$. By tuning the nano-cage wall thickness, the absorption peak can be changed from 400 to $1200 \mathrm{~nm}$ with an edge length in the range of $30-200 \mathrm{~nm}$. Gold colloidal nanospheres are widely being studied in hyperemia applications and image probe. Their small size and simple synthesis make them ideal for converting light into heat in the photothermal therapy (PTT) [40]. Au NPs can be used as a photothermal agent to generate tumor heating and can subsequently be depleted using laser exposure. Two Au nanorods are compared with single core and multicore. The generated heat was measured in water dispersion and in cancer cells using lasers at the wavelengths of 680, 808 and 1064 $\mathrm{nm}$. It is found that the Au nanospheres provide no significant heating in water while Au nanorods are efficient in the first biological window (NIR-I), and only nano-raspberries heat in the second biological window (NIR-II) [41]. The plasmonic superstructure of Au NPs can have enhanced photothermal effects and properties. For the case of dimer upon light illumination, they produce hot spots, which are very high electric fields at a small volume. Plasmonic coupling between two spheres in a dimer leads to an additional peak in the corresponding localized surface plasmon resonance spectrum [42].

With these encouraging recent developments, it can be expected that with the future development in synthetic technology, Au NPs will be more multifunctional and controllable in biomedical applications. External signals or stimuli such as magnetic field, light, heat and $\mathrm{pH}$ from the local environment will be able to modulate Au NPs, acting as an effective stimuli-responsive nano-devices for biomedical imaging, drug delivery and cancer therapy. 


\section{Cellular Uptake of Gold Nanoparticles and Cytotoxicity}

Nanoparticles are very small and comparable in size to many biomolecules. The properties of nanostructures are simple to modify to better suit their companion in a biological system. Gold particles that are modified with nuclear localization signal from simian virus (SV40) have been widely used for drug carrier to nucleus [43]. In many cases, the nano-peptide complex is injected directly into the cytoplasm near the nucleus. Tat peptide can be used to translocate Au NPs into the nucleus; recently, $\mathrm{Au}$ NP coated with mycobacterium, and a cell penetrating peptide were used to penetrate a membrane bound compartment inside the HeLa cells, where Au NPs are attached with peptides via linking agent [44]. Study shows that cellular uptake of Au NPs is dependent on surface functionalization. Key factors that determine the cellular uptake are the nature of the ligand, molecular weight, and grafting density. The report also states that cellular uptake is not significantly dependent on the size of Au NPs as seen in the laser scanning confocal microscopy and flow cytometry. However, in multicellular tumor spheroids, the smaller Au NPs had higher cellular uptake and advantages [45]. The cellular uptake of Au NPs also depends on the NP shape and the type of cell. A study was conducted to examine the effect of Au NP shape on RAW264.7 cells. The experimental results showed that the Au NPs with triangle shapes are more efficient than the rod shape in RAW264.7 cellular uptake, while the star-shaped Au NPs had the lowest cellular uptake [46]. Figure 2A shows the cellular uptake of the Au NPs, and Figure 2B-D are transmission electron microscopy images indicating the localizations of $\mathrm{Au}$ NPs. It is seen from Figure 2 that the NPs were internalized as single particles after incubation and were uptaken in vacuoles. However, the particles were not found in the cell nucleus [46].

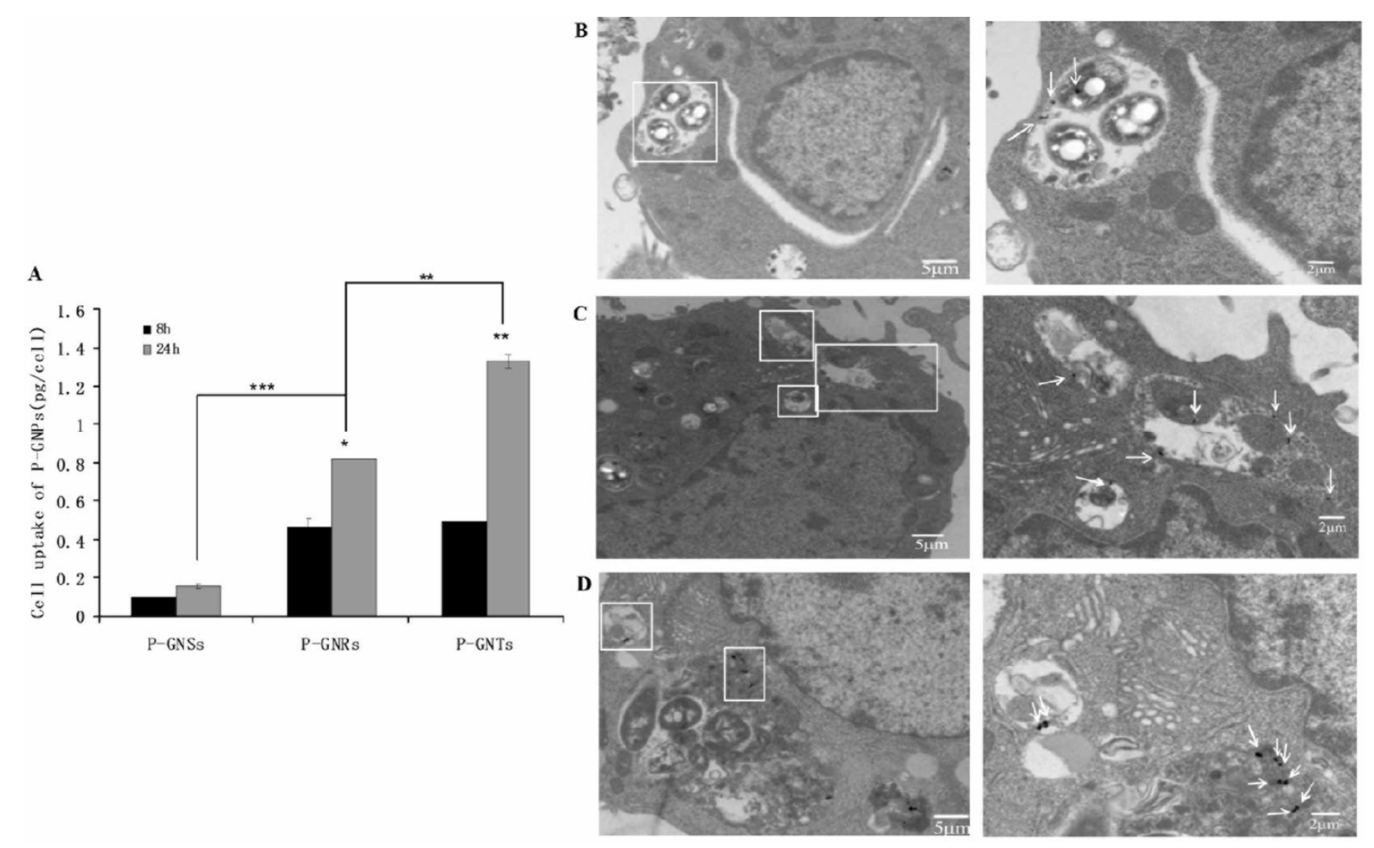

Figure 2. Cellular uptake of P-GNPs (A) and transmission electron microscopy images of RAW 264.7 after $24 \mathrm{~h}$ of incubation with P-GNSs (B), P-GNRs (C), P-GNTs (D). Data represent mean \pm SEM $(n=3)$. Statistical significance is represented by ${ }^{*} p<0.05,{ }^{* *} p<0.01,{ }^{* *} p<0.001$ [46]. Reproduced from reference [46] with Springer Nature under the Creative Commons Attribution 4.0 International License (https://creativecommons.org/licenses/by/4.0/).

Another study compares the post-transcriptional gene silencing, internalization, loading and release efficiencies with hollow Au nano-cages, nanorods and plasmons with siRNA. The result shows that nano-shells and nano-cages have the highest downregulation of green florescent protein after treatment. Hollow Au nano-shells load more than three times the amount of siRNA compared to nano-cages. The shape of the particle strongly affects the internalization of the Au NPs [47]. The Au 
NPs with sizes ranging from 5 to $50 \mathrm{~nm}$ were investigated for genotoxicity in vitro and in vivo assays. In the comet assay, 20 and $50 \mathrm{~nm}$ Au NPs were found to not induce significant DNA damage in the HepG2 cells. However, the $5 \mathrm{~nm}$ Au NPs gave rise to a dose-related enhancement in the DNA damage. The $5 \mathrm{~nm}$ Au NP caused the cell cycle arresting in the G1 phase to produce the DNA damage. In a chromosomal aberration test using the Chinese hamster lung cells, it did not show any significant aberration. For the in vivo micronucleus test, no significant increase in micronucleus formation was found in mice after 4 days of exposure. For the two weeks of exposure, however, the $5 \mathrm{~nm} \mathrm{Au} \mathrm{NPs}$ were found to have significant clastogenic damage with an increase in micronuclei frequencies due to the dose [48].

Cytotoxicity of most Au NPs depends on various parameters such as size, cell type, tissue distribution, tissue absorption, and penetration capacity. It was reported that small Au NPs (4-5 nm) have higher toxicity potential than large particles $(18-20 \mathrm{~nm}$ ) [49], and the size-dependent interaction between sub-nanometer Au NPs and the glycocalyx is relevant to the cellular uptake [50]. Research showed that Polyethylene Glycol-coated Au NPs had a transfection efficiency and cell uptake greater than $45 \%$ in each case with low cellular toxicity, and can be used as a DNA and drug delivery system reliably [51]. PEG is a common coating material used on Au NPs to reduce NP interaction with biological specimens. Research was carried out to investigate the effect of PEG on cellular uptake on three types of cells. The study also checked for the oxidative stress, cell morphology, and functionality. The result shows that PEG affects the cellular uptake of NP in a cell-dependent manner and influences toxicity by different mechanisms [52]. For in vivo toxicity, Cho et al [53] found that the $13 \mathrm{~nm}$ PEG-coated Au NPs induced acute inflammation and apoptosis in the human liver. Moreover, Lipka et al [54] carried out biokinetics studies on PEG-modified Au NPs. They found that after intravenous injection, a prolonged blood circulation time was found for the PEG-modified Au NPs, which mostly accumulated in the liver and spleen.

Multi drug resistance (MDR) has great influence on the success rate of cancer chemotherapy. A membrane-bound active drug efflux pump is a transporter that can efflux a wide range of anticancer agents. It is the most important mechanism involving MDR, and P-glycoprotein (P-gp). Most anticancer agents are stopped at the plasma membrane, where more inhibition or bypass of P-gp mediated drug efflux is important in MDR and drug delivery to the target cell. Au NPs are good quenchers for fluorescence donors due to the effect of surface energy transfer. This specific property allows Au NPs to become the base of the fluorescent nanoprobe. A drug system was developed, where doxorubicin was tethered onto the surface of Au NP with PEG through an acid labile linkage. This Au NP complex significantly overcame the P-gp mediated drug resistance due to the enhanced release of doxorubicin cellular entry and doxorubicin in acidic organelles. The intracellular responsive release was monitored by the recovery of fluorescence signals quenched by the Au NPs [55]. The cellular uptake of Au NPs is often dependent on the target molecule, and it can have a big impact on the treatment outcome. A study was carried out where the systematic delivery of siRNA to solid tumor in cervical cancer was investigated using unimer polyion complex Au NP, and targeting ligand cyclic Arg-Gly-Asp specifically binds to $\alpha \mathrm{v} \beta 3 / \alpha \mathrm{v} \beta 5$ integrins, which are overexpressed in cancer cells. The in vivo result shows that the targeting ligand has higher uptake by the cancer HeLa cells and shows significantly enhanced gene silencing [56].

Genotoxicity, cytotoxicity and the apoptotic effect of Au NPs were observed in normal liver cells and cancer liver cells. Green Au NPs caused intracellular reactive oxygen species, reduced total glutathione, and mitochondrial membrane potential in both the cells in a dose dependent manner. $\mathrm{N}$-acetyl-L-cycteline inhibits the generation of reactive oxygen species in both cells after exposure. Maximum DNA damage was observed at $700 \mathrm{mg} / \mathrm{ml}$ green Au NPs after 1 day of exposure. Healthy cells are more sensitive to green Au NPs than liver cancer cells. In both cells, cytotoxicity and apoptosis are mediated through the oxidative stress [57].

In the liquid phase, electrical discharge plasma causes reactive species leading to rapid reactions such as the degradation of biopolymers. In a plasma treatment study, N,O carboxymethyl 
chitosan-stabilized Au NP was used to cause plasma-induced degradation, which leads to a decrease in the hydrodynamic diameter of carboxymethyl chitosan Au NPs from $400 \mathrm{~nm}$ to $100 \mathrm{~nm}$. It also results in a narrow NP size distribution with diameter ranging from $2 \mathrm{~nm}$ to $40 \mathrm{~nm}$. Overall plasma treated carboxymethyl chitosan Au NPs can significantly decrease the cell viability of breast cancer cells [58].

Therefore, from the above studies on the cellular uptake and cytotoxicity of Au NPs, Au NPs are biocompatible, chemically stable and possess low toxicity in humans. However, variations of NP effects in the cellular environment due to particle size, shape and surface chemistry show that more detailed investigations in NP cellular uptake, cytotoxicity and biomedical responses should be carried out, and these have great potential for further development.

\section{Gold Nanoparticle-Based Drug Delivery}

Nanomedicine demonstrates excellent clinical performance with good therapeutic effectiveness and less healthy tissue toxicity. Au NP-based drug delivery has gained considerable attention because of its prominent performance. Although no pharmaceutical approval of Au NPs regarding nano-drugs is officially marketed, many studies on this aspect are being carried out. A number of Au NP-based nano-drugs combined with other biomedical applications, including drug-conjugated Au NPs prepared for cancer therapy and tumor-targeting, are being studied [59]. Au NPs are known to be an effective nano-carrier for various drugs, such as peptides, plasmid deoxynucleic acids (pDNAs), proteins, small interfering ribonucleic acids (siRNAs), and chemo-therapeutic agents.

In most cases, the surface area of Au NPs is modified with a cationic polymer or functional group such as carboxyl, amine and thiol groups to increase the surface area or surface-to-volume ratio for carrying the drug. The engineered surface area allows the stable and effective immobilization of the drug on to the Au NPs. The drug encapsulated in the Au NP complexes is protected from enzyme degradation by serum proteins in the blood stream. Cell-specific targeting molecules can also be attached to the drug-Au NP complexes and deliver the drug to specific target cells [60]. Fucoidan is an immune-therapeutic function polymer and is mainly used in pharmaceutical applications. It has a wide range of biological activities, such as anticoagulant, antibacterial, antiviral, immunomodulatory, anti-tumor, anti-inflammatory, and antithrombotic effects. The Au NPs are synthesized using fucoidan, which has increased biocompatibility and nontoxicity more than regular methods using naturally occurring marine polymers such as chitosan and porphyran [61].

The synthesis of anticancer particle aptamers and Au NP-modified Morin pH-sensitive liposome with targeting properties was studied. Tumors with a $\mathrm{pH}$ lower than the normal tissue reduces the effectiveness of the drug. Au NPs can be used to deliver $\mathrm{pH}$-responsive drugs such as Morin safely to the target for high effectiveness. In vivo results show that Au NP-encapsulated Morin can inhibit tumor growth in xenograft mouse models and promote tumor apoptosis. Blood biochemistry test shows these materials exhibit acute toxicity [62]. Bacterial infection is still one of the major causes of morbidity and mortality. In the case of Staphylococcal infection, the antimicrobial activity of antibiotics against microbes is severely limited by poor membrane transport ability [63]. Other challenges that need to be overcome when administering antimicrobial drugs are their low water solubility, clearance in blood stream, rapid degradation and cytotoxicity to healthy tissues. Au NPs are used in diagnosis and for therapeutic purposes for this case because of their specific properties-such as their large surface-to-volume ratio, small size, stability over high temperatures and high reactivity to living cells. Gentamicin sulfate is an aminoglycoside and has a board range of antibacterial activities. However, gentamicin sulfate has some serious side effects such as ototoxicity and nephrotoxicity, which restrict its usage. It also does not make cell membrane efficiently and is highly soluble to water. Gentamicin can be used for the treatment of serious microbial infection when it is conjugated to Au NPs [64].

A new delivery system was developed where each Au NP is surrounded by many drug moieties, acting as an individual group against the microbial organisms and able to penetrate cell wall effectively. This ability allows Au NPs to deliver a large number of antibiotic molecules into cells at a highly localized volume [65]. In Bronchiolitis obliterans syndrome, mesenchymal cells are primarily responsible for the 
fibro obliteration of small airways. An engineered Au NP with everolimus is very effective at inhibiting the proliferation and increasing the apoptosis of mesenchymal cells [66]. Cyclic peptide-capped Au NPs as a drug delivery system are an attractive and efficient choice due to their cell penetrating properties. They differ from regular Au NPs in various ways, such as the hydrophobic residues in the peptides. They are formed to perturb and/or permeate cell membranes by interacting with hydrophobic residues, which allow molecular cargo to have higher uptake than the conventional delivery. The Au NP surface with cyclic peptide requires no chemical modification or functionalization, nor any covalent conjugation between biologically active molecules and capped Au NPs (CP-Au NPs). The hydrophobic amino acids in the peptide produce a pocket for the noncovalent entrapment of the drug. Amino acid residues in cyclic peptide act as concurrent reductants and capping agents. Linear peptides-that in the amino acid contain nitrogen heteroaromatics, which are effective metal binders-and CP-Au NPs combined with anticancer and antiviral drugs can be used as potential scaffolds for the production of noncovalent prodrugs [67].

Recently, many studies have been carried out to find new innovative solution to develop highly efficient and reproducible fluorescent contrast agents for targeting specific cells [68]. Gold nano-carrier-based platinum (II) and platinum (IV) drugs have enhanced the loading capability on the surface of the nano-carriers, and release in a pH-dependent environment. A study introduced a system with Au NP-based platinum drugs, and Aminoanthraquinone was incorporated into the unit, where they are both acting as fluoroprobes and DNA intercalators. The unit has distinct, unusual and remarkable DNA binding properties [69]. Au NPs are also used on deeper sections of the eye such as the retina. A study was carried out to investigate how Au NPs can be used to deliver drug and biomacromolecules to the eye and how they can be used as active therapeutic tools [70]. A cell membrane coating strategy opened new opportunities for multifunctional drug delivery platforms. A system was proposed-making use of Au NPs combined with blood cell membrane- that can be used in cancer therapy for melanoma. Platelet membrane-coated Au nano-stars conjugated with curcumin were evaluated for whether R/P-cGNS had improved anticancer efficacy. Red blood cell coating provided self-antigens, so it evaded clearance by macrophages and platelet membrane coating provided targetability. The results show that it can be an effective system for cancer therapy [71]. On the other hand, a study was conducted to introduce a system that loads up doxorubicin-loaded oligonucleotides attached to Au NPs as carriers in chemotherapy for prostate cancer. The result shows that this is a viable method and has promising potential [72]. Moreover, three mercaptopropionic acid-capped Au NPs in resistant leukemia K562/ADM cells were tested for carrier capability and biomarkers. The experimental result is also promising [73].

\subsection{Plasmid Deoxynucleic Acids Vector ( $p D N A s)$ Delivery}

DNA-functionalized Au NPs are widely used in biosensors and drug delivery. The DNA Au NP conjugate can affect DNA absorption and the function of the attached protein corona on the NP [74]. Polyvalent DNA-Au NP conjugate has been an efficient and universal nano-carrier for drug and gene delivery, used in over 50 types of primary and cancer cell lines in the past 10 years. The interaction with blood serum content and nuclease degradation are the two primary barriers that limit the effectiveness of the DNA-Au NP conjugate. Terminal PEGylation of the complementary DNA strand hybridized to a polyvalent DNA-Au NP conjugate can eliminate the nonspecific absorption of serum proteins and increase its resistance against DNase I-based degradation. This increases the efficiency while maintaining a high cellular uptake [75]. For recent studies in the functionalization of Au NPs with thiol-modification, oligonucleotides have made the design of sophisticated NPs and nanostructures. Oligonucleotides are considered superior ligands due to their biomedical relevance, versatility, selectivity, high specificity and ease of chemical manipulation. Oligonucleotide functionalized $\mathrm{Au}$ NPs have been used to create NP dimers, trimers and tetramers that have adjustable NP distances and mesoscale structures, which contain millions of NPs in a precise pattern. DNA materials can be bound to the Au NPs with covalent linkage, which enhances their stability under DNA denaturing 
conditions. Synthetic oligonucleotides can be modified by an azide or alkyne group when brought in proximity using a templating splint strand. Partial complementarity to modified oligonucleotides causes oligonucleotide hybridization and eventually catalyzes a ligation reaction. This method was used to create $\mathrm{Au} \mathrm{NP}$ dimers and trimers with a high production rate and was stable in DNA denaturing condition. These dimers have multiplexed synergistic function in a cellular environment. They can be directed to two mRNA targets, and simultaneously or independently deliver one or two anticancer drugs to the living cells [76].

For therapeutic purposes to deliver nucleic acids efficiently, we need delivery systems that can compact genetic materials and maintain structural integrity when overcoming different delivery barriers, which must unload the genetic material to the target. Au NPs are often coated with amphiphiles to better transport DNA materials. A study was conducted to observe the delivery of plasmid DNA (pDNA) using Au NP coated with pyridinium amphiphiles (SPYRIT-68). The shape and size of the NP impacted the cell and its uptake. A very high curvature can produce a higher cytotoxic profile through the membrane portion. The size and shape of the Au NPs also control the blending of NP to bilayer forming cation lipids such as Ole, which generally has a cylindrical structure. For this experiment, small Au NPs $(20 \mathrm{~nm})$ with typical curvature were used. The Au NPs were stabilized using amphiphilic triethyleneglycol mercaptan. Positively charged Au NPs were used for DNA compaction and Ole alone could fully compact the DNA at a $+35 \mathrm{mV}$. This synergistic compaction effect of $\mathrm{Au}$ NPs and Ole allows a decrease in charge ratio, while still providing a good compaction of pDNA [77]. DNA delivery encapsulated in Au NPs in nanogels has been introduced and showed improved results. Polymeric NPs, such as in a nanogel, is a versatile delivery system that can encapsulate and release various biomolecules in controllable ways, prohibit metal NP aggregation, and reduce cytotoxicity.

The reaction parameters of Poly(N-isopropylacrylamide)—such as concentration of the monomer and initiator, medium polarity and polymerization temperature-were investigated for biomedical and bioengineering applications [78]. In a study, a poly(N-isopropylacrylamide)-based nanogel was used as a template for Au NPs due to biocompatibility, and properties such as easy modification and thermo-responsiveness. The Au NPs were synthesized using the free radical polymerization method where the size change can be controlled by increasing the temperature. Au NPs were also synthesized using the sodium dodecyl sulfate surfactant method, seeding the solution which allows it to control the amount of Au NPs by varying the ratio of the nanogels [79]. Liposomes are vesicles that are non-immunogenic efficient and used in gene and drug delivery applications. In targeted DNA delivery, Cationic 1,2 dioleoyltrimethylammoniumpropane (DOTAP) lipid is used due to its ability to form lipoplex by electrostatic interaction. They are ideal for use in antibacterial drug delivery applications. PEG cannot be used with liposome, and the removal of PEG from liposome surface is essential for gene and drug delivery applications. For the Staphylococcus aureus bacteria, DOTAP encapsulated in Au NPs was functionalized using hydrogel, which was used to deliver the drug in bacteria [80]. Another study was carried out to investigate the blocking of specific genes using Bcl-2 DNAi-conjugated Au NPs in MCF-7 cells. The results show that this is a viable choice and has potential to be used in clinical applications [81]. Crotamine is a basic, 42-residue polypeptide obtained from snake venom which possesses cell penetrating properties, so a study was carried out to observe the preparation, purification, biochemical and biophysical analysis of venom. It was studied to be functionalized with Au NPs to deliver DNA [82]. A Y-type DNA-functionalized Au nanoprobe was introduced to identify telomerase and trigger drug release in cancer cells. The system involved Au NPs with the dense modification of a Y-type DNA molecular beacon on the surface. The beacon consists of an FAM-labeled single-strand DNA, telomerase primers, and a single-strand DNA of two templates. An anticancer agent drug molecule was inserted into the DNA double strand. In the presence of the telomerase primers, extend and mismatch DNA is released, leading to the emission of fluorescent light from FAM and releasing Dox [83]. A DNA-based platform that can self-assemble into targeted NIR responsive NP for cancer thermo-chemotherapy was introduced. It has three distinct functional 
components: Au nanorod, complementary DNA strands, and PEG. This system is capable of delivering DNA and performing heat conversion for PTT [84].

\subsection{Ribonucleic Acids (RNAs) Delivery}

The use of RNA macromolecules as therapeutic agents for HIV, delivered directly to the target site, shows promising results. Lymphocytes that are in the body are particularly difficult to transfect. Therefore, an RNA delivery system carried in Au NPs was designed to carry out the task. A PEGylated $\mathrm{Au} \mathrm{NP}$ scaffold covalently connected to thiol-modified oligoribonucleotide through a cleavable $\mathrm{N}$-succinimidyl 3-(2-puridyldithio) propionate (SPDP) linker molecule was used. Cationic polymer polyethyleneimine was used to coat the Au NPs to enhance cell entry and endosomal escape. A synthetic anti-CD4 cyclic targeting peptide was linked to the Au NPs via SPDP linker molecule, which enhanced the uptake and selectivity of speared non-target cells. Approximately 45,000 RNA strands were uptaken per lymphocyte. No antiviral activity was detected, so it is a promising solution in the HIV treatment [85]. In gene and cancer therapy, RNA interference mediated gene silencing show potential. A hairpin RNA delivery system was introduced where a functionalized Au nanorod effectively condenses small hairpin RNA into stable NP. This can efficiently target specific points of human brain cancer cells. The combination effect of endosomal escape and the efficient cleavage of the disulfide-cross-linked short polyethylenimines by the high intracellular glutathione content triggers rapid cytoplasma RNA release, which produces excellent RNA interference efficiency and low cytotoxicity. High stability and prolonged blood circulation was obtained by PEGylation, which allowed for the effective accumulation of carriers in targeted tumors, resulting in outstanding intra-tumor gene silencing efficiency in brain cells, and the theory was tested on tumor-bearing mice and showed promising results [86]. In glioblastoma, delivering appropriate drug concentrations to the brain is very challenging. A new method has been proposed that explores the potential of a nose-to-brain direct transport pathway to bypass the blood brain barrier. This idea utilizes the delivery of targeted theranostic polyfunctional gold-iron oxide NP surface loaded with therapeutic micro RNA to glioblastoma. This carrier can deliver chemotherapy drug temozolomide. The drug has been tested on mice and shows promising results and potential for clinical use [87]. Triple negative breast cancer patients generally have worse clinical outcomes due to the high rate of recurrence. A new method for treating this cancer was proposed where multilayered NPs carrying metastasis suppressor microRNA (miR780) are localized to the target cancer area. The efficient delivery of the RNA could reduce lung metastasis. In vivo studies of this approach show promising outcomes and potential in triple negative breast cancer [88]. For the treatment of ovarian cancer, Au NPs can be used to deliver DNA to the target site. The study also looks at the anticancer effect of DOX-DNA-Au NP on three ovarian cancer cell lines, namely, SK-OV-3, HEY A8, and A2780 using EZ-Cytox cell viability assay. The result shows that Dox-DNA-Au NP gives outstanding activity and can be a viable option for the cancer treatment [89].

\subsection{Small Interfering Ribonucleic Acids (siRNAs) Delivery}

Small interfering ribonucleic acids have vast therapeutic potential, therefore they opened up a lot of novel clinical research areas focusing on numerous applications [90]. For effective cancer treatment, small RNA interference is a promising strategy. However, it has some major complications-such as easy degradation of small interfering RNA. For the treatment to be viable, siRNA delivery requires a vector system that has excellent biocompatibility, specific target property and efficient transfection efficiency. For the case of delivering siRNA to glioblastoma cells, a PEI entrapped Au NP modified with arginine-glycine-aspartic (Arg-GLY-Asp, RGD) peptide through a PEG spacer as a vector for B-cell lymphoma-2 (Bcl-s) was used, and the effect was observed. The Au NPs were used to deliver enhanced green fluorescent protein (EGFP) reporter genes. This gene expression demonstrated the highest mean fluorescence at an N/P ratio of ten. The siRNA delivery was checked using the flow cytometry, protein expression level analysis, and confocal microscopic imaging. The outcome of the flow cytometry and confocal microscopic image were consistent with pDNA transfection performance, 
and the experimental results show that the siRNA-encapsulated Au NPs could deliver Bcl-2 siRNA to U87MG cells with good transfection efficiency, and were capable of specific gene silencing in the target cells using an RGD peptide-mediated pathway [91]. Prostate cancer is one of the leading causes of cancer related death in men, especially in patients who have developed metastatic castrate resistant disease with very limited therapeutic options available to them. Recent research shows that using siRNA to silence some genes has high potential in this treatment. However, there is a major barrier that needs to be dealt with. When using siRNA in therapy, the siRNA duplexes are very unstable and have very low cellular uptake efficiencies. These may induce immune system activation. Furthermore, without a target ligand, any cell within the body can be transfected, and this can cause serious harm and health consequences to healthy cells and body. Au NPs can overcome most of these barriers and can protect the siRNA from enzymatic degradation and mediate gene silencing. A study was conducted where Au NPs were coated with PEI and conjugated with targeting ligand anisamide that is bound to the sigma receptor overexpressed on the surface of prostate cancer cells. These Au NPs encapsulate the siRNA and uptake into PC3 prostate cancer cells. It resulted in the highly efficient knockdown of the ReIA gene. The result shows that it is a viable option for therapeutic use [92]. Melanoma has a very high mortality rate and is related to the proliferation of pigment-producing melanocytes in epidermis. It is normally treated with surgical restriction and chemotherapy. Study shows that these cancer cells start to demonstrate resistance to the chemotherapeutic agents. Signal transduction and activator of transcription factor 3 (STAT3) seem to be constitutively active in most melanomas, and need to be targeted for tumor control. There is no clinically approved small molecule inhibitor of STAT3, but siRNA can be used to silence the gene. A therapeutic system where the co-delivery of anti-STAT3 siRNA, and imatinib mesylate encapsulated in Au NPs was proposed to silence the gene. Experimental results using this method showed a significant reduction in percentage tumor volume $(p<0.05)$, and weight [93]. On the other hand, breast cancer is one of the most common cancers in women and has a high risk of tumor recurrence and metastasis. The cancer stem-like cells (CSCs) are highly involved in drug resistance, metastasis, and relapse of the tumor due to their self-renewal ability and multilineage differentiation capacity. siRNA can be used in the sequence-specific silencing of RNA-coding cancer-related proteins in cells. CSCs are inert to traditional chemotherapeutic agents due to their resistance mechanisms such as multidrug efflux transporters. CSCs are sensitive to drugs that can target survival signals in RNA. A therapy model was introduced where glucose installed sub-50 nm unimer polymer complex-assembled Au NPs were used to deliver siRNA to a CSC-rich breast cancer model. A tumor-targeting ligand was added for more efficient binding to the target cells based on ligand-receptor interactions, and this can decrease the side effects on normal tissue. The results showed the high cellular uptake of siRNA in a spheroid breast cancer (MBA-MB-231) cell culture, which was able to efficiently and significantly silence the target gene in CSC-rich orthotopic MDA-MB-231 tumor tissue. Therefore, this can be a viable method in the future for CSC-targeted cancer treatment [94]. Another study on the gene expression profiling of cancer cells shows that breast adenocarcinomas express high levels of ROR1 antigen. ROR1 is a type one orphan receptor tyrosine-kinase. ROR1 signaling pathways are involved in cell proliferation and migration. Treatment with ROR1 siRNA can potentially mitigate the invasive properties of cancerous cells. A delivery system for siRNA based on HIV-1 TAT peptide-capped Au NPs was developed to treat breast cancer. Au NPs have a high affinity to sulfur, so peptide can be conjugated to Au NPs through Au-s bonds, and positively charged NPs show high cellular uptake. Therefore, a low concentration of NPs can be used with highly efficient gene transfection and low cytotoxicity. This study shows that it can be a viable treatment method for invasive breast cancer [95].

For the unique properties of Au NPs that can contribute to cancer therapy, numerous studies on Au NP-based drug delivery are carried out due to the multivalence and functional versatility of the $\mathrm{Au}$ NP conjugates. Drug delivery using Au NPs as carriers has the advantages of longer circulatory halftime, better biocompatibility, enhanced binding affinity, and internalization within cancer cells. 
Future studies will focus more on the Au NP-induced cytotoxicity and the NP interaction with the healthy cells.

\section{Gold Nanoparticle-Based Therapy}

Photothermal therapy (PTT) is a form of cancer therapy where NPs are embedded within the tumor and generate heat in response to exogenously applied laser light. Research shows that PTT is highly effective at cancer treatment. In addition, Au NPs are mostly used for PTT due to their superior biocompatibility, simple Au thiol bioconjugation chemistry for the attachment of desire molecules, small diameter that enable tumor penetration, efficient light to heat conversion, and the ability to be tuned to absorb near infrared light, which penetrates tissue more deeply than other light wavelengths. PPT is being implemented with other therapies as a combination, such as with chemotherapy and gene regulation [96]. Au NPs are promising in cancer theranostics due to their superior synthesis, modification and biocompatibility. The localized surface plasmon resonance and multivalent coordination effects on the NP surface are ideal for photothermal imaging, therapy-controlled drug release and targeted drug delivery [97]. NIR light has photons of longer wavelengths and less energy. NIR light penetrates deeper into living tissue but cannot carry out large amounts of photothermal reaction without external energy. However, Au NPs can convert NIR light into heat, which can then be applied to a specific site for hyperthermia. Hence, utilizing the $\mathrm{Au}$ NPs as photothermal agent can release heat which can damage or ablate tumor cells directly [98]. In chemo-photothermal synergetic cancer therapy, the co-delivery of multi-agents is being studied, where NPs can be used for drug delivery and photothermal effect. It shows promising results in breast cancer mouse models [99]. In cancer therapy, cell target imaging and efficient therapy are vital for tumor diagnosis and treatment. Multifunctional plasmonic NPs with high performance surface-enhanced Raman scattering (SERS)-imaging and NIR light-triggered plasmonic photothermal therapy of cancer cells in both the NIR-I and NIR-II were studied. The results show that Au nano-stars possess a broad NIR absorption band that covers both the NIR-I and NIR-II windows with good NIR SERS activity and photothermal effects. These nano-stars were designed to be multifunctional nano-agents by labeling Raman and conjugating arginine-glycine-aspartic acid, which serves as a cell targeted SERS-imaging tag. In vitro studies on A549 human lung adenocarcinoma cells show that these multifunctional nano-stars have high potential in SERS mapping and a wide spectrum of light mediated applications [100]. A customized hybrid and NIR light-triggered thermal responsive drug delivery system was introduced, where bupivacaine was used as a model drug, and Au hollow NPs were used as carriers. Their temperature responsiveness was studied and can be useful in PTT [101]. NIR-absorbing NPs, for use as photothermal cancer therapeutic agents, have been promising. A study was carried out to observe the properties of $\mathrm{Au}$-Au sulfide NIR-absorbing NPs that provide higher absorption as well as better tumor penetration. They have the ability to ablate tumor cells in vitro and are effective for photothermal cancer therapy. The results show a significant increase in long-term tumor free survival [102].

$\mathrm{Au}$ NPs can also be used as a dose enhancer in cancer radiotherapy. When Au NPs are added to the patient, dose enhancement at tumor can increase the cancer cell kill while sparing the critical tissues surrounding the tumor. Figure 3 shows the dependences of dose enhancement factor (DER) vs. Au NP concentration for different prostate sizes using the $6 \mathrm{MV}$ FFF (Figure 3A) and FF (Figure 3B) photon beams. It can be seen that the DER value increased with a reduction in prostate size. Moreover, higher DER values could be obtained by using the FFF (Figure 3A) photon beams compared to the FF (Figure 3B) [1]. 

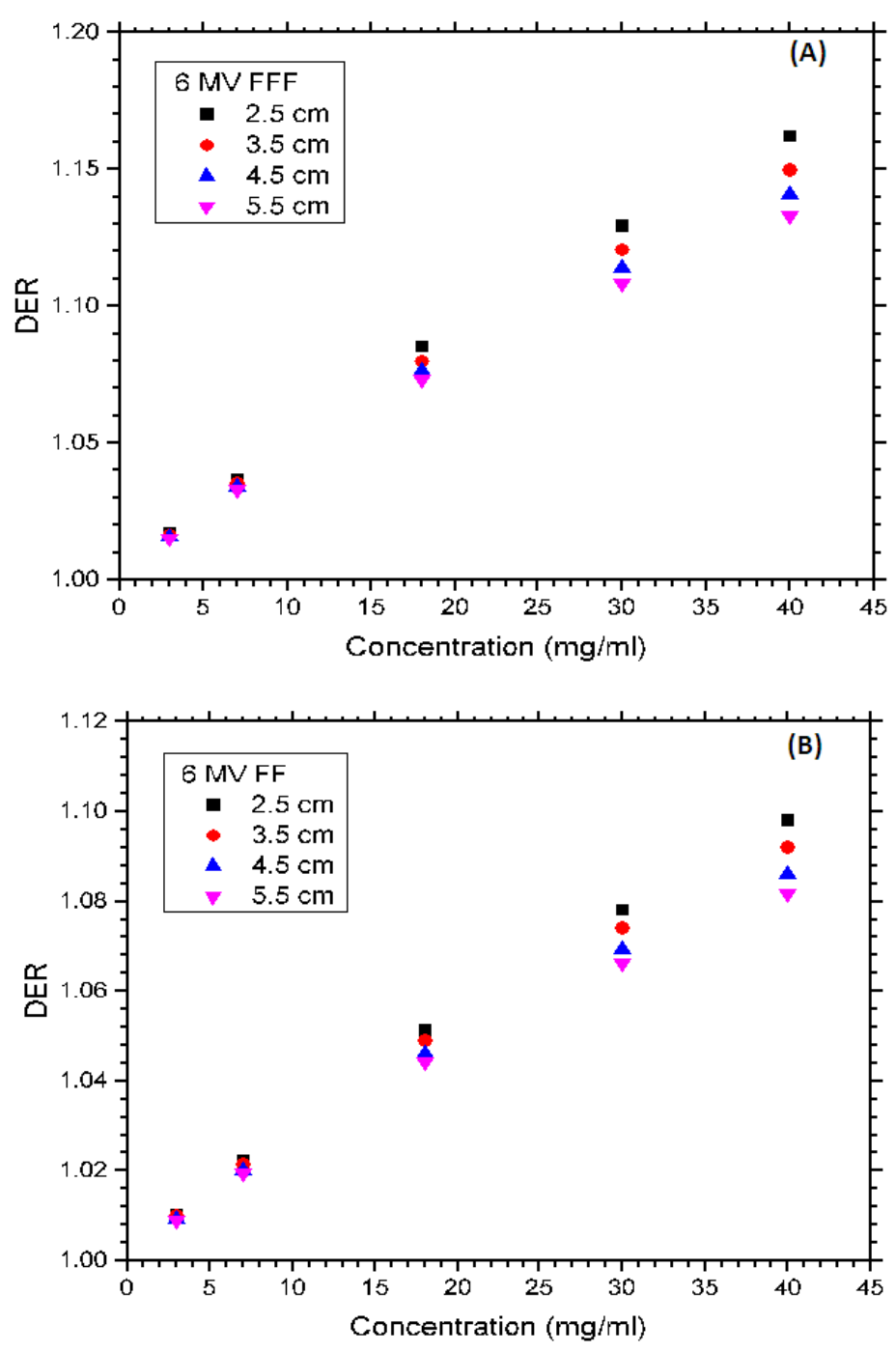

Figure 3. Relationship of the DER and Au NP concentrations, varying with different prostate sizes in the phantom using the $6 \mathrm{MV}$ (A) FFF and (B) FF photon beams. Au NPs with concentrations equal to 3, $7,18,30$, and $40 \mathrm{mg} / \mathrm{mL}$ were used. The DER was calculated as the ratio of the target dose with NP addition to the target dose without NP addition [1].

For skin cancer radiotherapy, Au NPs are added to the skin lesion with different thicknesses irradiated by different energies of $\mathrm{kV}$ photon beams. It is seen in Figure 4 that the DER values increased with a reduction in lesion thickness from 5 to $0.5 \mathrm{~mm}$. Moreover, DER value was higher when a lower energy of photon beam (i.e., $105 \mathrm{kVp}$, Figure $4 \mathrm{~A}$ ) was used in therapy compared to the $220 \mathrm{kVp}$ beam (Figure 4B) [103]. 

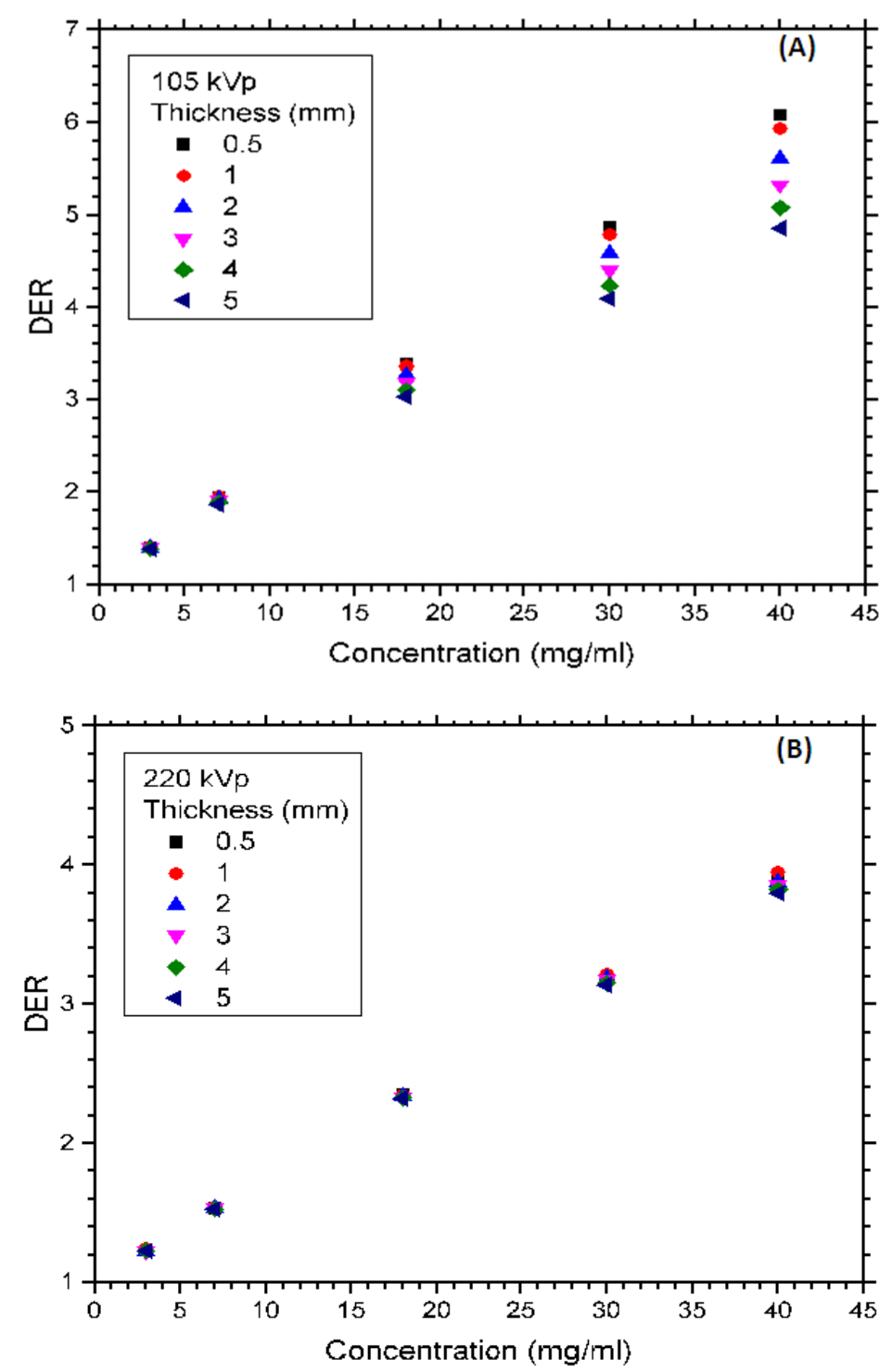

Figure 4. Relationship between the dose enhancement ratio and Au NP concentration with variation of the skin target thickness using the 105 (A) and $220 \mathrm{kVp}$ (B) photon beams [103].

Although it is proved by the experiments and Monte Carlo simulation that Au NPs can enhance the dose deposition and image contrast in the Au-loaded tumor, more cell-line and small-animal experiments are needed to further verify the relationship between the dose enhancement and various $\mathrm{NP}$ variables such as particle concentration, size, shape and distribution pattern.

\section{Molecular Nanoprobes}

NPs interact with light and have strong tunable surface plasmon resonance, which can be detected using multiple imaging modalities [104]. Au NPs have the ability to passively accumulate on tumor cells. Au NPs are an attractive contrast agent for X-ray-based computed tomography imaging. Their capabilities of producing photoacoustic signal and photothermal effect are also very valuable in medical imaging and diagnostics [105]. Au NPs have optical properties that are useful in biosensors in living cells. Surface plasmon resonance scattering image for Au NPs conjugated to monoclonal anti-epidermal growth factor (anti-EGFR) receptor antibodies in non-malignant epithelial cell line (HaCAT), and two malignant oral epithelial cell lines (HOC 313 clone 8 and HSC 3) were studied. The antibody conjugated NPs specifically and homogeneously bind to the surface of the cancer type cell with $600 \%$ greater 
affinity than to the noncancerous cells. This yields a sharper SPR absorption band with a red shifted maximum compared to that of the noncancerous cell. SPR scattering image generated from this antibody conjugated Au NPs are useful for diagnosis [106]. Ultra-small Au NPs less than $10 \mathrm{~nm}$ in diameter have proven to be promising in biomedical field. Their potential applications in cancer treatment and medical imaging have not yet been reviewed. There are several systems under development based on ultra-small Au NPs for use in diagnosis and cancer therapy. Some applications being developed include using ultra-small Au NPs for tumor visualization and bio-imaging in different fields such as magnetic resonance imaging, fluorescence imaging, photoacoustic imaging and x-ray scatter imaging. They are also being studied in tumor chemotherapy, radiotherapy and gene therapy [107].

\section{Conclusions}

$\mathrm{Au}$ NPs have high potential in cancer therapy and drug delivery applications. Even though Au NPs are not being widely used for clinical applications, the researches on Au NP-based drug delivery, gene therapy, photothermal therapy and radiotherapy all show promising results, and they have proven to be potential viable solutions in the future. From the propitious results at present and expected progress in future, it is certain that Au NPs will continue to play a significant role in improving the biomedical field, such as in drug delivery and cancer therapy. However, some limitations on the Au NP application as nanocarriers or radiosensitizers—such as cytotoxicity, nonbiodegradability, and the modulation of cellular responses—should not be neglected, and need to be investigated in detail.

Author Contributions: Conceptualization, J.C.L.C.; methodology, J.C.L.C. and S.S.; resources, S.S.; writing — original draft preparation, S.S.; writing—review and editing, J.C.L.C. and S.S.; visualization, J.C.L.C.; supervision, J.C.L.C.; project administration, J.C.L.C. All authors have read and agreed to the published version of the manuscript.

Funding: This research received no external funding.

Conflicts of Interest: The authors declare no conflict of interest.

\section{References}

1. Martelli, S.; Chow, J.C.L. Dose Enhancement for the Flattening-Filter-Free and Flattening-Filter Photon Beams in Nanoparticle-Enhanced Radiotherapy: A Monte Carlo Phantom Study. Nanomaterials 2020, $10,637$. [CrossRef] [PubMed]

2. Mututantri-Bastiyange, D.; Chow, J.C.L. Imaging dose of cone-beam computed tomography in nanoparticle-enhanced image-guided radiotherapy: A Monte Carlo phantom study. AIMS Bioeng. 2020, 7, 1-11. [CrossRef]

3. Chow, J.C.L. Monte Carlo Nanodosimetry in Gold Nanoparticle-Enhanced Radiotherapy. In Recent Advancements and Applications in Dosimetry; Chan, M.F., Ed.; Nova Science Publishers: New York, NY, USA, 2018; Chapter 2.

4. Jain, S.; Hirst, D.G.; O'Sullivan, J.M. Gold nanoparticles as novel agents for cancer therapy. Br. J. Radiol. 2012, 85, 101-113. [CrossRef] [PubMed]

5. Chow, E.K.; Ho, D. Cancer Nanomedicine: From Drug Delivery to Imaging. Sci. Transl. Med. 2013, 5, 216 rv4. [CrossRef] [PubMed]

6. Abdulle, A.; Chow, J.C.L. Contrast Enhancement for Portal Imaging in Nanoparticle-Enhanced Radiotherapy: A Monte Carlo Phantom Evaluation Using Flattening-Filter-Free Photon Beams. Nanomaterials 2019, 9, 920. [CrossRef] [PubMed]

7. Alkilany, A.; Murphy, C. Toxicity and cellular uptake of gold nanoparticles: what we have learned so far? J. Nanopart. Res. 2010, 12, 2313-2333. [CrossRef] [PubMed]

8. Jurj, A.; Braicu, C.; Pop, L.-A.; Tomuleasa, C.; Gherman, C.D.; Berindan-Neagoe, I. The new era of nanotechnology, an alternative to change cancer treatment. Drug Des. Dev. Ther. 2017, 11, 2871-2890. [CrossRef]

9. Lavacchi, D.; Roviello, G.; D'Angelo, A. Tumor-Agnostic Treatment for Cancer: When How is Better than Where. Clin. Drug Investig. 2020, 40, 519-527. [CrossRef] 
10. Kong, F.-Y.; Zhang, J.-W.; Li, R.-F.; Wang, Z.-X.; Wang, W.-J.; Wang, W. Unique Roles of Gold Nanoparticles in Drug Delivery, Targeting and Imaging Applications. Molecules 2017, 22, 1445. [CrossRef]

11. Chow, J.C.L. Application of Nanoparticle Materials in Radiation Therapy. In Handbook of Ecomaterials; Martinez, L.M.T., Kharissova, O.V., Kharisov, B.I., Eds.; Springer Nature: Basel, Switzerland, 2017; Chapter 150; pp. 3661-3681.

12. Chow, J.C.L. Photon and electron interactions with gold nanoparticles: a Monte Carlo study on gold nanoparticle-enhanced radiotherapy. In Nanobiomaterials in Medical Imaging: Applications of nanobiomaterials; Grumezescu, A.M., Ed.; Elsevier: Amsterdam, The Netherlands, 2016; Chapter 2; pp. 45-70.

13. Chow, J.C.L. Recent Progress of Gold Nanomaterials in Cancer Therapy. In Handbook of Nanomaterials and Nanocomposites for Energy and Environmental Applications; Kharissova, O.V., Torres-Martínez, L.M., Kharisov, B.I., Eds.; Springer Nature: Cham, Switzerland, 2020; pp. 1-30.

14. Wuttke, S.; Lismont, M.; Escudero, A.; Rungtaweevoranit, B.; Parak, W.J. Positioning metal-organic framework nanoparticles within the context of drug delivery-A comparison with mesoporous silica nanoparticles and dendrimers. Biomaterials 2017, 123, 172-183. [CrossRef]

15. Abbas, M.; Alqahtani, M.; AlGahtani, A.; Kessentini, A.; Loukil, H.; Parayangat, M.; Ijyas, T.; Mohammed, A.W. Validation of Nanoparticle Response to the Sound Pressure Effect during the Drug-Delivery Process. Polymers 2020, 12, 186. [CrossRef] [PubMed]

16. Liz-Marzán, L.M. Gold nanoparticle research before and after the Brust-Schiffrin method. Chem. Commun. 2013, 49, 16-18. [CrossRef] [PubMed]

17. Bai, X.; Wang, Y.; Song, Z.; Feng, Y.; Chen, Y.; Zhang, D.; Feng, L. The Basic Properties of Gold Nanoparticles and their Applications in Tumor Diagnosis and Treatment. Int. J. Mol. Sci. 2020, 21, 2480. [CrossRef] [PubMed]

18. Dumur, F.; Dumas, E.; Mayer, C. Functionalization of Gold Nanoparticles by Inorganic Entities. Nanomaterials 2020, 10, 548. [CrossRef] [PubMed]

19. Katti, K.V. Renaissance of nuclear medicine through green nanotechnology: functionalized radioactive gold nanoparticles in cancer therapy-My journey from chemistry to saving human lives. J. Radioanal. Nucl. Chem. 2016, 309, 5-14. [CrossRef]

20. Baptista, P.V.; Fernandes, A.R.; Figueiredo, S.; Vinhas, R.; Cordeiro, M.; Carlos, F.F.; Mendo, S. Gold nanoparticle-based theranostics: disease diagnostics and treatment using a single nanomaterial. Nanobiosens. Dis. Diagn. 2015, 4, 11. [CrossRef]

21. Slepička, P.; Kasálková, N.S.; Siegel, J.; Kolská, Z.; Švorčík, V. Methods of Gold and Silver Nanoparticles Preparation. Materials 2019, 13, 1. [CrossRef]

22. Sau, T.K.; Murphy, C. Role of ions in the colloidal synthesis of gold nanowires. Philos. Mag. 2007, 87, 2143-2158. [CrossRef]

23. Austin, L.; Mackey, M.A.; Dreaden, E.C.; El-Sayed, M.A. The optical, photothermal, and facile surface chemical properties of gold and silver nanoparticles in biodiagnostics, therapy, and drug delivery. Arch. Toxicol. 2014, 88, 1391-1417. [CrossRef]

24. Adams, S.; Zhang, J.Z. Unique optical properties and applications of hollow gold nanospheres (HGNs). Co-ord. Chem. Rev. 2016, 320, 18-37. [CrossRef]

25. Brust, M.; Walker, M.; Bethell, D.; Schiffrin, D.J.; Whyman, R. Synthesis of thiol-derivatised gold nanoparticles in a two-phase Liquid?Liquid system. J. Chem. Soc. Chem. Commun. 1994, 7, 801. [CrossRef]

26. Zhao, J.; Friedrich, B. Synthesis of Gold Nanoparticles Via the Chemical Reduction Methods; Shaker: Oak Park, IL, USA, 2017.

27. Kim, C.; Ghosh, P.; Rotello, V. Multimodal drug delivery using gold nanoparticles. Nanoscale 2009, 1, 61-67. [CrossRef] [PubMed]

28. Kimling, J.; Maier, M.; Okenve, B.; Kotaidis, V.; Ballot, H.; Plech, A. Turkevich Method for Gold Nanoparticle Synthesis Revisited. J. Phys. Chem. B 2006, 110, 15700-15707. [CrossRef] [PubMed]

29. Wen, S.; Zheng, F.; Shen, M.; Shi, X. Synthesis of polyethyleneimine-stabilized gold nanoparticles for colorimetric sensing of heparin. Colloids Surf. A Physicochem. Eng. Asp. 2013, 419, 80-86. [CrossRef]

30. Ortega-Muñoz, M.; Girón, M.D.; Salto, R.; Reyes, A.B.J.; De Jesus, S.; Lopez-Jaramillo, F.J.; Hernandez-Mateo, F.; Santoyo-Gonzalez, F. Polyethyleneimine-Coated Gold Nanoparticles: Straightforward Preparation of Efficient DNA Delivery Nanocarriers. Chem. Asian J. 2016, 11, 3365-3375. [CrossRef] 
31. Jokerst, J.V.; Lobovkina, T.; Zare, R.N.; Gambhir, S.S. Nanoparticle PEGylation for imaging and therapy. Nanomedicine 2011, 6, 715-728. [CrossRef]

32. Amoozgar, Z.; Yeo, Y. Recent advances in stealth coating of nanoparticle drug delivery systems. Wiley Interdiscip. Rev. Nanomed. Nanobiotechnol. 2012, 4, 219-233. [CrossRef]

33. Sengani, M.; Grumezescu, A.M.; Rajeswari, V.D. Recent trends and methodologies in gold nanoparticle synthesis-A prospective review on drug delivery aspect. OpenNano 2017, 2, 37-46. [CrossRef]

34. Zhao, L.; Jiang, D.; Cai, Y.; Ji, X.; Xie, R.; Yang, W. Tuning the size of gold nanoparticles in the citrate reduction by chloride ions. Nanoscale 2012, 4, 5071. [CrossRef]

35. Cortez-Lemus, N.A.; Licea-Claverie, A.; Paraguay-Delgado, F.; Alonso-Nuñez, G. Gold nanoparticles size design and control by poly(N,N'-diethylaminoethyl methacrylate). J. Nanomater. 2015. [CrossRef]

36. Brinas, R.P.; Hu, M.; Qian, L.; Lymar, E.S.; Hainfeld, J.F. Gold Nanoparticle Size Controlled by Polymeric Au(I) Thiolate Precursor Size. J. Am. Chem. Soc. 2008, 130, 975-982. [CrossRef] [PubMed]

37. Kasture, M.; Sastry, M.; Prasad, B.L.V. Halide ion controlled shape dependent gold nanoparticle synthesis with tryptophan as reducing agent: Enhanced fluorescent properties and white light emission. Chem. Phys. Lett. 2010, 484, 271-275. [CrossRef]

38. Langille, M.R.; Personick, M.L.; Zhang, J.; Mirkin, C.A. Defining Rules for the Shape Evolution of Gold Nanoparticles. J. Am. Chem. Soc. 2012, 134, 14542-14554. [CrossRef]

39. Coughlin, A.; West, J. Gold nanoshells for imaging and photothermal ablation of cancer. In Nanomedicine; Elsevier BV: Amsterdam, The Netherlands, 2012; pp. 326-355.

40. Kennedy, L.; Bickford, L.R.; Lewinski, N.A.; Coughlin, A.J.; Hu, Y.; Day, E.S.; West, J.L.; Drezek, R.A. A New Era for Cancer Treatment: Gold-Nanoparticle-Mediated Thermal Therapies. Small 2010, 7, 169-183. [CrossRef]

41. Sangnier, A.P.; Van De Walle, A.; Aufaure, R.; Fradet, M.; Motte, L.; Guénin, E.; Lalatonne, Y.; Wilhelm, C. Endosomal Confinement of Gold Nanospheres, Nanorods, and Nanoraspberries Governs Their Photothermal Identity and Is Beneficial for Cancer Cell Therapy. Adv. Biosyst. 2020, 4, e1900284. [CrossRef] [PubMed]

42. Gellner, M.; Steinigeweg, D.; Ichilmann, S.; Salehi, M.; Schütz, M.; Kömpe, K.; Haase, M.; Schlücker, S. 3D Self-Assembled Plasmonic Superstructures of Gold Nanospheres: Synthesis and Characterization at the Single-Particle Level. Small 2011, 7, 3445-3451. [CrossRef] [PubMed]

43. Wang, T.; Zhang, Z.; Gao, D.; Li, F.; Wei, H.; Liang, X.; Cui, Z.; Zhang, X.-E. Encapsulation of gold nanoparticles by simian virus 40 capsids. Nanoscale 2011, 3, 4275-4282. [CrossRef]

44. Mandal, D.; Maran, A.; Yaszemski, M.J.; Bolander, M.E.; Sarkar, G. Cellular uptake of gold nanoparticles directly cross-linked with carrier peptides by osteosarcoma cells. J. Mater. Sci. Mater. Electron. 2008, 20, 347-350. [CrossRef]

45. Lu, H.; Su, J.; Mamdooh, R.; Li, Y.; Stenzel, M.H. Cellular Uptake of Gold Nanoparticles and Their Movement in 3D Multicellular Tumor Spheroids: Effect of Molecular Weight and Grafting Density of Poly(2-hydroxyl ethyl acrylate). Macromol. Biosci. 2019, 20, e1900221. [CrossRef]

46. Xie, X.; Liao, J.; Shao, X.; Li, Q.; Lin, Y. The Effect of shape on Cellular Uptake of Gold Nanoparticles in the forms of Stars, Rods, and Triangles. Sci. Rep. 2017, 7, 3827. [CrossRef]

47. Morgan, E.; Wupperfeld, D.; Morales, D.P.; Reich, N.O. Shape Matters: Gold Nanoparticle Shape Impacts the Biological Activity of siRNA Delivery. Bioconj. Chem. 2019, 30, 853-860. [CrossRef] [PubMed]

48. Xia, Q.; Zhang, S.; Feng, Q.; Xiao, K.; Li, H.; Liu, Y. The effect of particle size on the genotoxicity of gold nanoparticles. J. Biomed. Mater. Res. Part A 2016, 105, 710-719. [CrossRef] [PubMed]

49. Zhang, X.-D.; Wu, D.; Shen, X.; Liu, P.-X.; Yang, N.; Zhao, B.; Zhang, H.; Sun, Y.-M.; Zhang, L.-A.; Fan, F.-Y. Size-dependent in vivo toxicity of PEG-coated gold nanoparticles. Int. J. Nanomed. 2011, 6, 2071-2081. [CrossRef] [PubMed]

50. Du, B.; Jiang, X.; Das, A.; Zhou, Q.; Yu, M.; Jin, R.; Zheng, J. Glomerular barrier behaves as an atomically precise bandpass filter in a sub-nanometer regime. Nat. Nanotechnol. 2017, 12, 1096. [CrossRef] 
51. Zamora-Justo, J.A.; Abrica-González, P.; Vázquez-Martínez, G.R.; Muñoz-Diosdado, A.; Balderas-López, J.A.; Ibáñez-Hernández, M. Polyethylene Glycol-Coated Gold Nanoparticles as DNA and Atorvastatin Delivery Systems and Cytotoxicity Evaluation. J. Nanomater. 2019, 2019, 1-11. [CrossRef]

52. Soenen, S.J.; Manshian, B.B.; Abdelmonem, A.; Montenegro, J.-M.; Tan, S.; Balcaen, L.; Vanhaecke, F.; Brisson, A.R.; Parak, W.J.; De Smedt, S.C.; et al. The Cellular Interactions of PEGylated Gold Nanoparticles: Effect of PEGylation on Cellular Uptake and Cytotoxicity. Part. Part. Syst. Charact. 2014, 31, 794-800. [CrossRef]

53. Cho, W.-S.; Cho, M.; Jeong, J.; Choi, M.; Cho, H.-Y.; Han, B.-S.; Kim, S.H.; Kim, H.O.; Lim, Y.T.; Chung, B.H.; et al. Acute toxicity and pharmacokinetics of $13 \mathrm{~nm}$-sized PEG-coated gold nanoparticles. Toxicol. Appl. Pharmacol. 2009, 236, 16-24. [CrossRef]

54. Lipka, J.; Semmler-Behnke, M.; Sperling, R.; Wenk, A.; Takenaka, S.; Schleh, C.; Kissel, T.; Parak, W.J.; Kreyling, W.G. Biodistribution of PEG-modified gold nanoparticles following intratracheal instillation and intravenous injection. Biomaterials 2010, 31, 6574-6581. [CrossRef]

55. Wang, F.; Wang, Y.; Dou, S.; Xiong, M.-H.; Sun, T.-M.; Wang, J. Doxorubicin-Tethered Responsive Gold Nanoparticles Facilitate Intracellular Drug Delivery for Overcoming Multidrug Resistance in Cancer Cells. ACS Nano 2011, 5, 3679-3692. [CrossRef]

56. Yi, Y.; Kim, H.J.; Mi, P.; Zheng, M.; Takemoto, H.; Toh, K.; Kim, B.G.; Hayashi, K.; Naito, M.; Matsumoto, Y.; et al. Targeted systemic delivery of siRNA to cervical cancer model using cyclic RGD-installed unimer polyion complex-assembled gold nanoparticles. J. Control. Release 2016, 244, 247-256. [CrossRef]

57. Bin-Jumah, M.N.; Al-Abdan, M.; Al-Basher, G.; Alarifi, S. Molecular Mechanism of Cytotoxicity, Genotoxicity, and Anticancer Potential of Green Gold Nanoparticles on Human Liver Normal and Cancerous Cells. Dose-Response 2020, 18. [CrossRef] [PubMed]

58. Chokradjaroen, C.; Rujiravanit, R.; Theeramunkong, S.; Saito, N. Effect of electrical discharge plasma on cytotoxicity against cancer cells of N,O-carboxymethyl chitosan-stabilized gold nanoparticles. Carbohydr. Polym. 2020, 237, 116162. [CrossRef] [PubMed]

59. Wang, W.; Wang, J.; Ding, Y. Gold nanoparticle-conjugated nanomedicine: design, construction, and structure-efficacy relationship studies. J. Mater. Chem. B 2020. [CrossRef] [PubMed]

60. Jeong, E.H.; Jung, G.; Hong, C.A.; Lee, H.-J. Gold nanoparticle (AuNP)-based drug delivery and molecular imaging for biomedical applications. Arch. Pharmacal Res. 2013, 37, 53-59. [CrossRef]

61. Manivasagan, P.; Bharathiraja, S.; Bui, N.Q.; Jang, B.; Oh, Y.-O.; Lim, I.G.; Oh, J. Doxorubicin-loaded fucoidan capped gold nanoparticles for drug delivery and photoacoustic imaging. Int. J. Boil. Macromol. 2016, 91, 578-588. [CrossRef]

62. Ding, X.; Yin, C.; Zhang, W.; Sun, Y.; Zhang, Z.; Yang, E.; Sun, D.; Wang, W. Designing Aptamer-Gold Nanoparticle-Loaded pH-Sensitive Liposomes Encapsulate Morin for Treating Cancer. Nanoscale Res. Lett. 2020, 15, 1-17. [CrossRef]

63. Zharov, V.P.; Mercer, K.E.; Galitovskaya, E.N.; Smeltzer, M.S. Photothermal Nanotherapeutics and Nanodiagnostics for Selective Killing of Bacteria Targeted with Gold Nanoparticles. Biophys. J. 2006, 90, 619-627. [CrossRef]

64. Yeluri, T.; Bhosale, R.S.; Ghule, N.V.; Raynor, A.M.; Bhosale, S.V.; Bhosale, S.V. Neomycin and gentamicin detection via molecular recognition with cyclam-decorated gold nanoparticles. Supramol. Chem. 2015, 27, 772-779. [CrossRef]

65. Ahangari, A.; Salouti, M.; Heidari, Z.; Kazemizadeh, A.R.; Safari, A.A. Development of gentamicin-gold nanospheres for antimicrobial drug delivery to Staphylococcal infected foci. Drug Deliv. 2013, 20, 34-39. [CrossRef]

66. Meloni, F.; Cova, E.; Inghilleri, S.; Oggionni, T.; Magni, S.; Morosini, M.; Briganti, D.; Colombo, M.; Agozzino, M.; De Angelis, M.C.; et al. Novel Antibody-Engineered Gold Nanoparticles as Targeted Drug Delivery for Primary Mesenchimal Cells Do Not Elicit an Inflammatory Response. J. Hear. Lung Transpl. 2014, 33, S166. [CrossRef]

67. Shirazi, A.N.; Mandal, D.; Tiwari, R.K.; Guo, L.; Lu, W.; Parang, K. Cyclic Peptide-Capped Gold Nanoparticles as Drug Delivery Systems. Mol. Pharm. 2012, 10, 500-511. [CrossRef] [PubMed]

68. Borlan, R.; Tatar, A.-S.; Soritau, O.; Maniu, D.; Marc, G.; Florea, A.; Focsan, M.; Astilean, S. Design of fluorophore-loaded human serum albumin nanoparticles for specific targeting of NIH:OVCAR3 ovarian cancer cells. Nanotechnology 2020, 31, 315102. [CrossRef] 
69. Caballero, A.B.; Cardo, L.; Claire, S.; Craig, J.S.; Hodges, N.J.; Vladyka, A.; Albrecht, T.; Rochford, L.A.; Pikramenou, Z.; Hannon, M.J. Assisted delivery of anti-tumour platinum drugs using DNA-coiling gold nanoparticles bearing lumophores and intercalators: towards a new generation of multimodal nanocarriers with enhanced action. Chem. Sci. 2019, 10, 9244-9256. [CrossRef] [PubMed]

70. De Matteis, V.; Rizzello, L. Noble Metals and Soft Bio-Inspired Nanoparticles in Retinal Diseases Treatment: A Perspective. Cells 2020, 9, 679. [CrossRef]

71. Kim, M.W.; Lee, G.; Niidome, T.; Komohara, Y.; Lee, R.; Park, Y.I. Platelet-Like Gold Nanostars for Cancer Therapy: The Ability to Treat Cancer and Evade Immune Reactions. Front. Bioeng. Biotechnol. 2020, 8, 133. [CrossRef] [PubMed]

72. Lee, C.S.; Kim, H.; Yu, J.; Yu, S.H.; Ban, S.; Oh, S.; Jeong, D.; Im, J.; Baek, M.J.; Kim, T.H. European Journal of Medicinal Chemistry Doxorubicin-loaded oligonucleotide conjugated gold nanoparticles: A promising in vivo drug delivery system for colorectal cancer therapy. Eur. J. Med. Chem. 2017, 142, 416-423. [CrossRef]

73. Li, J.; Wang, X.; Wang, C.; Chen, B.; Dai, Y.; Zhang, R.; Song, M.; Lv, G.; Fu, D. The Enhancement Effect of Gold Nanoparticles in Drug Delivery and as Biomarkers of Drug-Resistant Cancer Cells. ChemMedChem 2007, 2, 374-378. [CrossRef]

74. Wu, R.; Peng, H.; Zhu, J.-J.; Jiang, L.-P.; Liu, J. Attaching DNA to Gold Nanoparticles With a Protein Corona. Front. Chem. 2020, 8, 121. [CrossRef]

75. Song, L.; Guo, Y.; Roebuck, D.; Chen, C.; Yang, M.; Yang, Z.; Sreedharan, S.; Glover, C.; Thomas, J.A.; Liu, N.; et al. Terminal PEGylated DNA-Gold Nanoparticle Conjugates Offering High Resistance to Nuclease Degradation and Efficient Intracellular Delivery of DNA Binding Agents. ACS Appl. Mater. Interfaces 2015, 7, 18707-18716. [CrossRef]

76. Kyriazi, M.-E.; Giust, D.; El-Sagheer, A.H.; Lackie, P.M.; Muskens, O.L.; Brown, T.; Kanaras, A.G. Multiplexed mRNA Sensing and Combinatorial-Targeted Drug Delivery Using DNA-Gold Nanoparticle Dimers. ACS Nano 2018, 12, 3333-3340. [CrossRef]

77. Kizewski, A.; Ilies, M.A. Efficient and synergetic DNA delivery with pyridinium amphiphiles-gold nanoparticle composite systems having different packing parameters. Chem. Commun. 2016, 52, 60-63. [CrossRef] [PubMed]

78. Mackova, H.; Jendelova, P. Effects of the reaction parameters on the properties of thermosensitive poly(N-isopropylacrylamide) microspheres prepared by precipitation and dispersion polymerization. J. Polym. Sci. Part A Polym. Chem. 2005, 44, 968-982. [CrossRef]

79. Udomluck, N.; Baipaywad, P.; Lee, S.H.; Park, H. Poly( $\mathrm{N}$-isopropylacrylamide)-based nanogels encapsulating gold nanoparticles for DNA delivery. J. Control. Release 2015, 213, e85. [CrossRef] [PubMed]

80. Bhuvana, M.; Dharuman, V. Influence of alkane chain lengths and head groups on tethering of liposome-gold nanoparticle on gold surface for electrochemical DNA sensing and gene delivery. Sens. Actuators B Chem. 2016, 223, 157-165. [CrossRef]

81. Karimi, S.; Fouani, M.H.; Moshaii, A.; Nikkhah, M.; Hosseinkhani, S.; Sheikhnejad, R. Development of Dual Functional Nucleic Acid Delivery Nanosystem for DNA Induced Silencing of Bcl-2 Oncogene. Int. J. Nanomed. 2020, 15, 1693-1708. [CrossRef] [PubMed]

82. Hayashi, M.A.F.; Campeiro, J.D.; Porta, L.C.; Szychowski, B.; Alves, W.A.; Oliveira, E.B.; Kerkis, I.; Daniel, M.-C.; Karpel, R.L. Crotamine Cell-Penetrating Nanocarriers: Cancer-Targeting and Potential Biotechnological and/or Medical Applications. Methods Mol. Biol. 2020, 2118, 61-89. [CrossRef]

83. Zhang, S.; Liang, K.; Li, P.; Liu, J.; Tang, B. Application of a Y-type-DNA-functionalized nanogold probe featuring specific telomerase recognition and doxorubicin release in cancer cells. Analyst 2020, 145, 2152-2158. [CrossRef]

84. Xiao, Z.; Ji, C.; Shi, J.; Pridgen, E.M.; Frieder, J.; Wu, J.; Farokhzad, O.C. DNA self-assembly of targeted near-infrared-responsive gold nanoparticles for cancer thermo-chemotherapy. Angew. Chem. Int. Ed. 2012, 51, 11853-11857. [CrossRef]

85. Parboosing, R.; Govender, T.; Maguire, G.E.M.; Kruger, H.G. Synthesis, Characterization and Biocompatibility of a Multifunctional Gold Nanoparticle System for the Delivery of Single-Stranded RNA to Lymphocytes. S. Afr. J. Chem. 2018, 71, 1-14. [CrossRef]

86. Wang, F.; Zhang, W.; Shen, Y.; Huang, Q.; Zhou, D.; Guo, S. Efficient RNA delivery by integrin-targeted glutathione responsive polyethyleneimine capped gold nanorods. Acta Biomater. 2015, 23, 136-146. [CrossRef] 
87. Sukumar, U.K.; Bose, R.J.; Malhotra, M.; Babikir, H.A.; Afjei, R.; Robinson, E.; Zeng, Y.; Chang, E.; Habte, F.; Sinclair, R.; et al. Intranasal delivery of targeted polyfunctional gold-iron oxide nanoparticles loaded with therapeutic microRNAs for combined theranostic multimodality imaging and presensitization of glioblastoma to temozolomide. Biomaterials 2019, 218, 119342. [CrossRef] [PubMed]

88. Ramchandani, D.; Lee, S.K.; Yomtoubian, S.; Han, M.S.; Tung, C.-H.; Mittal, V. Nanoparticle Delivery of miR-708 Mimetic Impairs Breast Cancer Metastasis. Mol. Cancer Ther. 2019, 18, 579-591. [CrossRef] [PubMed]

89. Lee, S.-W.; Park, S.-M.; Kim, Y.-M.; Kim, Y.S.; Choi, E.K.; Kim, D.-Y.; Kim, J.-H.; Nam, J.-H.; Kim, Y.T. Radiation therapy is a treatment to be considered for recurrent epithelial ovarian cancer after chemotherapy. Tumori J. 2011, 97, 590-595. [CrossRef]

90. Artiga, Á.; Sevilla, I.S.; De Matteis, L.; Mitchell, S.G.; De La Fuente, J.M. Current status and future perspectives of gold nanoparticle vectors for siRNA delivery. J. Mater. Chem. B 2019, 7, 876-896. [CrossRef] [PubMed]

91. Kong, L.; Qiu, J.; Shi, X. Multifunctional PEI-entrapped gold nanoparticles enable efficient delivery of therapeutic siRNA into glioblastoma cells. J. Control. Release 2017, 259, e83-e84. [CrossRef]

92. Fitzgerald, K.A.; Rahme, K.; Guo, J.; Holmes, J.D.; O’Driscoll, C.M. Anisamide-targeted gold nanoparticles for siRNA delivery in prostate cancer - synthesis, physicochemical characterisation and in vitro evaluation. J. Mater. Chem. B 2016, 4, 2242-2252. [CrossRef]

93. Labala, S.; Jose, A.; Chawla, S.R.; Khan, M.S.; Bhatnagar, S.; Kulkarni, O.P.; Venuganti, V.V.K. Effective melanoma cancer suppression by iontophoretic co-delivery of STAT3 siRNA and imatinib using gold nanoparticles. Int. J. Pharm. 2017, 525, 407-417. [CrossRef]

94. Yi, Y.; Kim, H.J.; Zheng, M.; Mi, P.; Naito, M.; Kim, B.S.; Min, H.S.; Hayashi, K.; Perche, F.; Toh, K.; et al. Glucose-linked sub-50-nm unimer polyion complex-assembled gold nanoparticles for targeted siRNA delivery to glucose transporter 1-overexpressing breast cancer stem-like cells. J. Control. Release 2019, 295, 268-277. [CrossRef]

95. Ahwazi, R.P.; Kiani, M.; Dinarvand, M.; Assali, A.; Tekie, F.S.M.; Dinarvand, R.; Atyabi, F. Immobilization of HIV-1 TAT peptide on gold nanoparticles: A feasible approach for siRNA delivery. J. Cell. Physiol. 2019, 235, 2049-2059. [CrossRef]

96. Riley, R.S.; Day, E.S. Gold nanoparticle-mediated photothermal therapy: applications and opportunities for multimodal cancer treatment. Wiley Interdiscip. Rev. Nanomed. Nanobiotechnol. 2017, 9, e1449. [CrossRef]

97. Chen, W.; Zhang, S.; Yu, Y.; Zhang, H.; He, Q. Structural-Engineering Rationales of Gold Nanoparticles for Cancer Theranostics. Adv. Mater. 2016, 28, 8567-8585. [CrossRef] [PubMed]

98. Wang, J.; Wu, X.; Shen, P.; Wang, J.; Shen, Y.; Shen, Y.; Webster, T.J.; Deng, J. Applications of Inorganic Nanomaterials in Photothermal Therapy Based on Combinational Cancer Treatment. Int. J. Nanomed. 2020, 15, 1903-1914. [CrossRef] [PubMed]

99. Liu, M.; Huang, P.; Wang, W.; Feng, Z.; Zhang, J.; Deng, L.; Dong, A. An injectable nanocomposite hydrogel co-constructed with gold nanorods and paclitaxel-loaded nanoparticles for local chemo-photothermal synergetic cancer therapy. J. Mater. Chem. B 2019, 7, 2667-2677. [CrossRef] [PubMed]

100. Song, C.; Li, F.; Guo, X.; Chen, W.; Dong, C.; Zhang, J.; Zhang, J.; Wang, L.; Chen, N. Gold nanostars for cancer cell-targeted SERS-imaging and NIR light-triggered plasmonic photothermal therapy (PPTT) in the first and second biological windows. J. Mater. Chem. B 2019, 7, 2001-2008. [CrossRef]

101. Ortiz de Solorzano, I.; Mendoza, G.; Arruebo, M.; Sebastian, V. Customized hybrid and NIR-light triggered thermoresponsive drug delivery microparticles synthetized by photopolymerization in a one-step flow focusing continuous microreactor. Colloids Surf. B Biointerfaces 2020, 190, 110904. [CrossRef]

102. Gobin, A.M.; Watkins, E.M.; Quevedo, E.; Colvin, V.L.; West, J.L. Near-Infrared-Resonant Gold/Gold Sulfide Nanoparticles as a Photothermal Cancer Therapeutic Agent. Small 2010, 6, 745-752. [CrossRef]

103. Zheng, X.J.; Chow, J.C.L. Radiation dose enhancement in skin therapy with nanoparticle addition: A Monte Carlo study on kilovoltage photon and megavoltage electron beams. World J. Radiol. 2017, 9, 63-71. [CrossRef]

104. Wang, Z. Plasmon-resonant gold nanoparticles for cancer optical imaging. Sci. China Ser. G Phys. Mech. Astron. 2013, 56, 506-513. [CrossRef]

105. Zhao, N.; Pan, Y.; Cheng, Z.; Liu, H. Gold nanoparticles for cancer theranostics-A brief update. J. Innov. Opt. Health Sci. 2016, 9, 1630004. [CrossRef] 
106. El-Sayed, I.H.; Huang, X.; El-Sayed, M.A. Surface Plasmon Resonance Scattering and Absorption of anti-EGFR Antibody Conjugated Gold Nanoparticles in Cancer Diagnostics: Applications in Oral Cancer. Nano Lett. 2005, 5, 829-834. [CrossRef]

107. Fan, M.; Han, Y.; Gao, S.; Yan, H.; Cao, L.; Li, Z.; Liang, X.-J.; Zhang, J. Ultrasmall gold nanoparticles in cancer diagnosis and therapy. Theranostics 2020, 10, 4944-4957. [CrossRef] [PubMed] 